\title{
El fin del modelo urbano y municipal en Arucci Turobriga. La transformación hacia la antigüedad tardía (ss. III-VII d.c.)'
}

\author{
The end of the urban and municipal model in Arucci Turobriga. The transfor- \\ mation towards the late antiquity (IIIrd-VIInd B.C.)
}

Javier Bermejo Meléndez *

\begin{abstract}
RESUMEN
Desde fines del s. II y a lo largo de todo el s. III se desarrollaron en el imperio una serie de profundas transformaciones económicas, políticas y sociales cuyas consecuencias tuvieron en última instancia la caída y desaparición del ordenamiento municipal y urbano en numerosas ciudades a lo largo de todo el territorio. Para el caso de la ciudad de Arucci Turobriga, iniciado el s. III, ésta dará muestras de actividad y continuidad en la vida municipal, sin embargo a medida que avance la centuria perderá su pulso de manera progresiva manteniendo una población cada vez menor, que amortizará los espacios con nuevas funcionalidades siendo ocupada probablemente hasta el s.V d.C.
\end{abstract}

Palabras Clave: Tardoantiguedad, Bajoimperio, Arucci Turobriga, crisis

\section{Introducción y Contexto Histórico}

Inaugurado el s. III d.C. el pulso de la vida urbana y municipal entrará en crisis debido a numerosos factores y condicionantes que llevarán irremediablemente al agotamiento del modelo de la civitas, produciéndose el abandono de numerosos centros urbanos a lo largo de los siguientes decenios, así como la transformación de otros que pervivirán en el tiempo (ARCE, 1993: 243, 247). Durante este periodo las elites locales ya no verán la necesidad de asumir el coste del mantenimiento de las

\begin{abstract}
From ends of the Ind c. B.C. and along everything the Illrd century there developed in the empire a series of deep economic, political and social transformations which consequences had in last instance the fall and disappearance of the municipal and urban classification in numerous cities along the whole territory. For the case of Arucci Turobriga's city, initiated s. the IIIrd c., this one will give samples of activity and continuity in the municipal life, nevertheless as it advances the century it will lose his pulse of a progressive way keeping a population every time minor, that will amortize the spaces with new functionalities being occupied probably even s.V A.C.
\end{abstract}

KeyWords: Late antiquity, Late empire, Arucci Turobriga, crisis

instituciones municipales ante un poder central cada vez más débil y sumido en constantes pronunciamientos, los munera no serán objeto de interés, son vistos como onerosas cargas, con lo que la dinámica en el poblamiento se verá cada vez más volcada al ámbito rural, donde se retiran a sus villae, abandonando el ámbito de vida urbano y la ciudad a su suerte. Ya decenios antes, durante la segunda mitad del s. Il se comienzan a vislumbrar los primeros síntomas de estancamiento que preludian el colapso del sistema económico imperante, debido como causa directa al agotamiento de

\footnotetext{
* Área de Arqueología de la Universidad de Huelva.

I El presente trabajo se enmarca dentro de las actividades del Proyecto de Investigación de Excelencia del Plan Andaluz de Investigación "Ciudades Romanas del Territorio Onubense" (Ref. HUM 269l), y del Proyecto General de investigación de la Consejería de Cultura de la Junta de Andalucía "Investigación y puesta en valor de la ciudad hispanorromana de Turobriga".
} 
un modelo que se había vuelto insostenible, ahora se producirá la progresiva caída de la producción minera, que llevará incluso en momentos del s. II d.C. al abandono de cotos, endeudamiento público, gastos militares ante la inseguridad en las fronteras, invasiones, aumento del intervencionismo del estado, etc. (CHIC, 2005: 580-586). En esta dinámica desde fines del s. II d.C. la civitas, pilar clave del estado romano, entra en crisis dado que a partir de Hadriano la intervención estatal será mayor en este sistema, las oligarquías debían de pagar el honor que se les confería con una serie de liturgias que fueron evolucionando hasta tener un carácter de obligaciones periódicas, desapareciendo el espíritu evergético de periodos anteriores y convirtiéndose en motivo más para refugiarse en sus fundi (FORNELL, 2005: 594).

Para el caso bético más inmediato que nos ocupa, esto es, el área occidental, los acontecimientos desarrollados en los últimos decenios del s. II d.C., con las incursiones de mauri, las cuales se prolongarán con sucesivas oleadas durante el s. III aunque con menor intensidad (RODRÍGUEZ, 1972: 195), la inestabilidad en el territorio lusitano con constantes revueltas y el cambio de dinastía tras la desaparición de los antoninos habrían creado un ambiente de inseguridad que a buen seguro habría afectado a la vida municipal. Como consecuencia de este proceso, a lo largo del s.lll d.C., en la zona meridional de la antigua Baeturia Celtica se producirá un nuevo cambio en el patrón de asentamiento, donde el modelo urbano entra en crisis hasta su desaparición, volviéndose a un poblamiento disperso, enrarecido, que en nada debió parecerse a los momentos del s. |-Il d.C.

Por su parte, para el caso aruccitano (Fig. I), a medida que avance la centuria se irán manifestando los signos de decaimiento en el ámbito de la civitas, en un proceso irreversible de descomposición política y económica enmarcado en el contexto general de crisis, cada vez más acentuado, para a mediados del s. III haber perdido toda su funcionalidad. A este respecto, estarían haciendo alusión a estos momentos el cambio en la funcionalidad de los edificios, especialmente los públicos, ya que son éstos los que resultan de especial interés a la hora de comprender la dinámica que se desarrolla en el ámbito urbano mostrando los síntomas de la progresiva desaparición de la vida municipal. Así han sido varias las evidencias arqueológicas constatadas en determinados edificios que han venido a mostrar un uso de los espacios públicos ocupados ahora con una nueva funcionalidad, relacionados irremediablemente con el decaimiento en primer lugar, y la desaparición en segundo, del modelo urbano y las instituciones que lo sustentaban.

Paralelamente, el ager sufrirá también numerosas transformaciones, evolucionando hacia una nueva configuración, donde paulatinamente se podrá comprobar un descenso de las especies cultivadas, con un avance de la dehesa en detrimento de las zonas de cultivo, que irremediablemente lleva a ponerlo en relación con un descenso productivo, todo ello con el telón de fondo del estancamiento comercial, la consolidación o surgimiento de grandes fundi, así como de centros menores surgidos en torno a villae, que marcarán el patrón de asentamiento durante el s. III y IV d.C.

\section{El siglo III y la pérdida del ordenamiento municipal}

Son numerosos los indicadores de crisis, transformaciones y abandono que se pueden rastrear para estos momentos en los elementos y edificios que conforman el urbanismo de la ciudad.

En este sentido es el foro, quizás, el edificio que mejor representa la dinámica que exponemos en estas líneas ya que se aprecian en sus diversas estancias cambios que revelan sustanciales diferencias con respecto a etapas precedentes donde este conjunto muestra su momento de máxima actividad municipal y religioso (CAMPOS Y BERMEJO, 2007; BERMEJO, 20I0a). Así, durante los siglos I, II y comienzos del III d.C., éste verá en sus dependencias una ocupación funcional de manera ininterrumpida reservada a cuestiones administrativas, judiciales y religiosas las funciones para las que fueron diseñadas y construidas. 
En línea con nuestra argumentación en salas como la curia, los sacella de culto imperial, o la propia aedes, se deja sentir un pulso inconfundible en la actividad a la que estaban reservadas. Prueba de ello serían, por ejemplo, las manifestaciones de culto imperial detectadas en los exvotos de época severiana que reproducen modelos femeninos del momento, con una clara vinculación a las mujeres de la casa imperial imperante, Iulia Donna, Iulia Mammea, o en su defecto a las virtudes imperiales femeninas a las que quedan asociadas, concordia, pax, etc., pero que sin lugar a dudas muestran indicios de culto y actividad religiosa para un periodo en el que tradicionalmente se había relegado cualquier indicio de pervivencia de la vida urbana con todas las consideraciones, religiosas, políticas, y administrativas que encierra (BERMEJO, 20 IOb). Otro dato que puede revelarnos un ritmo, al menos de continuidad con respecto a etapas precedentes, para estos momentos de comienzos del s. III estaría representado por el material arquitectónico-decorativo conservado. Con ello hacemos alusión a un capitel corintio encuadrable, tras su análisis estilístico, en los momentos de fines del s. II d.C. y principios del III, encontrando numerosos paralelos en su factura con otros modelos emeritenses y cordobeses de este periodo (BERMEJO, 2007: 357, Lám. IV). El único argumento que podría explicar la existencia de una actividad constructiva en el foro, o en sus áreas públicas más inmediatas para estos momentos vendría de la mano de alguna posible refectio o reforma, dado que no se constata la construcción de ningún edificio público, sospechosamente relacionada con la nueva etapa constructiva y de decoración arquitectónica que sufren muchas ciudades de la bética ante la llegada de una nueva dinastía, muestra de la intención de unas clases dirigentes o aristocracias locales deseosas de exhibir su adhesión al poder reinante. De la evidencia de estos datos, se intuye por tanto, una continuidad en la actividad de la ciudad y las instituciones que la sostenían desde el punto de vista religioso y político, de lo que se deduce pues, que para momentos severianos las instituciones municipales que sostenían dichas manifestaciones, evergéticas, religiosas, etc. aún seguían activas, comprobando cómo las estancias reservadas para el culto mantenían su funcionalidad y que existía una población que aún encontraba en el mundo urbano de la civitas, el lugar donde expresar sus muestras de afecto y devoción, así como a buen seguro otras tantas actividades, comerciales, judiciales, etc.

Este ritmo irá en aumento y será probablemente en la segunda mitad de la centuria cuando se produzca el paulatino decaimiento de la actividad en el foro, produciéndose un abandono funcional de sus estancias. Será en estos momentos cuando se compartimente el pórtico doble, creando un conjunto de habitaciones en su ángulo sureste, con una actividad totalmente distinta, relacionada con una funcionalidad habitacional, doméstica y artesanal. Resulta difícil precisar un momento de construcción de las mismas, dado que no ha aparecido material que permita fechar el establecimiento de estas estancias, aunque sin duda responden a un momento en el que las funciones basilicales que acogía el pórtico doble estaban ya en desuso (Fig. 2).

Igualmente a este momento puede corresponder el cegamiento de la puerta del foro, construido con un muro de una factura similar a las compartimentaciones del pórtico doble, con material constructivo reaprovechado y manteniendo una buena disposición en el vano de acceso (Fig. 3).

De ello se deriva una pregunta interesante, dado que si el foro se constituyó en el momento de su construcción como un conjunto cerrado con un solo acceso, enmarcado de manera axial con respecto al conjunto, ipor dónde se realizaría el acceso para estos momentos tardíos? A este respecto la única interpretación válida, dado que no se constata la apertura de vanos en ninguno de los muros perimetrales, sería el considerar la existencia de otro posible acceso desde la calle a través de la basilica, adosada en su lateral sur y conectada con el foro desde el tribunal/aedes, el cual daba acceso a su vez a las habitaciones que se habían construido en estos momentos bajo el porticado doble.

Paralelamente en distintas dependencias se están produciendo remodelaciones que hablan 
de cambios en el uso de las mismas. De este modo en la sala de los ediles se construye un muro con una factura y técnica edilicia muy similar a los de aquellos de las compartimentaciones del porticado doble, reaprovechando material latericio, piedras de tamaños irregulares, que compartimenta la estancia en dos (Fig. 4).

¿Por qué se produce esta división? Podríamos apuntar, al igual que para el caso de las compartimentaciones en el porticado doble, la pérdida de funcionalidad de esta sala, es decir el reaprovechamiento con nuevos usos, en unos momentos de mediados del s. III d.C., en los que las funciones del edilato no tienen representación ni se necesitan, no tanto por una falta de población, que a buen seguro la tendría, sino más bien por el agotamiento y colapso definitivo del modelo de gestión y administración municipal. Similar episodio se documenta en la curia, donde se construye un muro en uno de sus laterales creando una pequeña división del espacio, en un momento correspondiente al segundo cuarto del s. III d.C., como se desprende del análisis de las sigillatae africana tipo Hayes 42 (220-240/50) asociadas a dicho muro. Es pues que cuando se produce esta compartimentación, el ordo decurionum es solo un recuerdo de la organización municipal, el cual habría dejado de constituirse para momentos del segundo cuarto del s. III d.C., dada las evidencias y el contexto.

Es por ello que en la sala de los ediles y la curia encontramos uno de los indicios más significativos en relación a este periodo, dado que desde ellas se administraba la ciudad, una acogiendo la sede del edilato y sus funciones, control de pesos, monedas, precios, multas o sanciones municipales, calendario, etc., y otra el ordo decurionum, máximo símbolo del poder municipal, con lo que la remodelación de la salas, aprovechadas con otros usos en un momento indeterminado de mediados del s. III d.C., está indicando de manera indirecta que al menos para esos momentos la vida municipal había dejado de existir. Además con posterioridad al periodo de actividad que se constata en el foro para comienzos del s. III, no existen indicios, manifestaciones religiosas, evergéticas, ni por supuesto un ambiente epigráfico posterior a los severos, como si se constatan en otras ciudades de la Betica, Astigi a Aureliano (270-275) Constancio y Maximiano, Corduba a Valeriano y Galieno (253-268), Tucci a Claudio II (269), Italica a Floriano (276), etc. que evidencien una actividad municipal y urbana 2 .

Sin embargo, pese a la desaparición de la vida municipal y sus órganos de gobierno, podemos argumentar la existencia de una ocupación del área forense a lo largo del s. III con una posible continuidad, de una manera residual, hasta elV d.C., tal y como demuestran algunas formas tardías en determinados espacios donde documentamos sigillatae africanas de formas Hayes 50 y 69 (DELGADO, 2007: 357). Obviamente ello nos está indicando un aprovechamiento de algunos espacios de la ciudad, en este caso el foro, para momentos tardíos, lo que denota una cierta población en el antiguo solar urbano.

Con todo, y a la luz del análisis de los espacios forenses (Fig. 5), donde residían las funciones municipales, podemos establecer que entre el reinado de los severos y aproximadamente mediados del s. III pudo darse el colapso del modelo urbano y de gestión administrativo, político y religioso propios de la ciudad.

Por lo que respecta al área residencial, el número de intervenciones desarrolladas en la zona ha sido uno de los más escasos en comparación con otras zonas como el foro o las termas, además, debido al factor tiempo muchos sectores de excavación correspondiente a esta área quedaron por excavar, delimitándose sólo algunas manzanas.

Así, de las dos casas que con certeza se han podido documentar, la casa de la columna y la casa norte, tan solo la primera de ellas ha

2 Las referencias epigráficas de estas manifestaciones son; CILA II, 69I, 692; CIL II, 2199; I672; III5 
mostrado una secuencia completa ${ }^{3}$ desde el s. I d.C. hasta los primeros decenios del s. III, mostrando claros síntomas de cambio en sus estructuras y dependencias desde momentos de fines del s. II d.C. Con todo, la denominada casa de la Columna mostrará síntomas de ocupación en momentos indeterminados del s. III d.C., dado que tan solo se documenta algún fragmento de sigillata africana tipo Hayes 44, sin que esté apoyado por otros tipos comunes propios de estos momentos, Almagro $5 \mathrm{lcl}$ Keay 23, Almagro 50/Keay 16, lo que evidencia un mínimo ocupacional para estos momentos. Obviamente no podríamos transpolar la secuencia detectada en una sola casa al resto de las viviendas de la ciudad, debiendo esperar a nuevas excavaciones que puedan aportar más datos sobre estos momentos de ocupación o abandono. De cualquier forma, sea como fuere, las primeras evidencias apuntan a un abandono progresivo de esta casa, siendo probablemente un edificio en ruinas antes de el s. IV d.C., lo que coincide a grandes rasgos con los datos que proporciona el contexto general en zonas como la muralla.

En este último elemento una de las primeras características que llama la atención es la diversidad de aparejos y calidad constructiva que se aprecia en los diferentes trazados hasta la fecha exhumados. A este respecto existen tramos de muralla de una buena calidad, realizados en opus incertum, dotando al lienzo de una gran solidez, a la vez que se apreciaban buenas cimentaciones en las esquinas realizadas con sillares, componiendo las caras de la muralla y un núcleo de caementum y cascotes. Junto a estos tramos bien cuidados en aparejo y técnica constructiva, llamaba la atención varios sectores tremendamente arrasados hasta su cimentación, apenas conservando dos o tres hiladas de piedras, en los que se podía apreciar una calidad constructiva muy pobre y deficiente, donde la principal característica era la utilización de materiales muy diversos. En este sentido en uno de los sectores de muralla localizados al oeste, junto a la necrópolis norte, se documentaron unos nueve metros en la que se habían empleado material pétreo irregular, numeroso material constructivo, tégulas, ladrillos, ímbrices, y grandes fragmentos de mármol correspondiente a fustes de columnas. De todo ello se podía deducir una construcción deficiente, totalmente diferenciada de otros tramos o sectores, dando la impresión de un descuidado aparejo, debido a la necesidad y a la premura, en el que se habían empleado numerosos materiales, incluido el mármol proveniente del material decorativo y arquitectónico. Similar impresión causaba la documentación de este tipo de material noble en otro sector de muralla ubicado en el quiebro que toma ésta en su sector noreste, donde se habían empleado bloques de mármol en el paramento de la muralla, reutilizados y retallados ex profeso.

Todos estos datos podrían estar haciendo alusión a una reforma o restauración en los lienzos de muralla para momentos de fines del s. II y comienzos del III d.C. debido a la inestabilidad política y defensiva que se desata en el imperio durante los últimos antoninos, especialmente en la Bética (ARCE, 1981: I01). Es más puede que la ciudad incluso no tuviera completamente cerrado el perímetro de la muralla, para tiempos del s. I y || d.C., ya que no es necesario, como puede ser el caso de Munigua (SCHATNER, 2004) y que debido a las inseguridades de la segunda mitad del s. II d.C., en estrecha relación con las revueltas de la Lusitania y el Bellum Mauricum, que afectó a lugares tan próximos de la Betica como Munigua, o Italica, tuviera que cerrar su muralla a prisa y reaprovechando todo tipo de materiales (ARCE, 1981: 107; CORELL, 1988: 302). Para el caso de Munigua se constató una situación similar a la documentada en Arucci Turobriga, en la construcción de su muralla, en la que se trazó su recorrido seccionando la necrópolis sur, reutilizando materiales provenientes de la misma, como lápidas, aras, etc. lo que denotaba pocos miramientos y una prisa latente ante el

3 Ello es debido a que fue posible la realización de sondeos estratigráficos en los que se pudieron documentar diferentes fases, gracias a un mayor periodo de tiempo de excavación. 
acoso del tiempo. Esta construcción así como sus características fue puesta en relación con los episodios de inseguridad que se vivieron por la invasión de pueblos del norte de áfrica (GRÜNHAGEN, 1982: 320, 321).

El territorio onubense muestra evidencias de posibles episodios de pillaje y asalto probablemente debidos a la acción de estas incursiones de mauri, o incluso a los raids que tuvieron como protagonistas en la segunda mitad del III a francos y Alamanes, en sitios próximos como Riotinto, donde se constata la destrucción del edificio de representación y las esculturas de culto (PÉREZ, 2006: 106), o evidencias tan llamativas como la ocultación del tesorillo aparecido en 1948 en la Finca de la Plata (cañada del Tesoro) en Valverde del Camino, próxima a un área minera, y que contenía unos 800 antoninianos de Gordiano III, Valeriano I y Galieno (BALIL, 1957: 142). Con ello no queremos decir que el territorio aruccitano viera la incursión de algún tipo de invasión o revuelta, posibilidades que tampoco deberían ser denostadas dado que se tienen constatadas como vemos evidencias en áreas próximas, sino que más bien la situación de inseguridad propia de estos momentos ante las noticias que desde el Valle del Guadalquivir y el área minera llegarían se decide actuar sobre la antigua muralla de la ciudad. Esta restauración de los lienzos de muralla, no durará demasiado, ya que en torno a la década de los 50/60 del s. III mostrará un estado ruinoso, con algunos derrumbes en parte de su recorrido, máxime si se tiene en cuenta las distintas calidades en la factura, tal y como quedó constatado en el sector noreste fechado por un antoniano de Claudio II el gótico (268-270) en un nivel de derrumbe y expolio (Fig. 6).

Fuera de las murallas de la ciudad, y de igual modo que en el foro, en el campus, pese a ser un conjunto con un menor número de intervenciones, se ha podido documentar una fase correspondiente a un momento impreciso del s. III ○ IV d.C, representada por el cierre parcial de la puerta del recinto. En este sentido se construye un muro que estrecha el antiguo acceso al campus, dejando un vano de apenas un metro, reduciendo así los dos metros y medio que originariamente tenía. La técnica edilicia de este muro es muy pobre, incluso peor a la documentada en el cegamiento de la puerta del foro, con una disposición de mampuestos irregulares y material latericio todo ello trabado a hueso (Fig. 7).

Esta fase nos está hablando de un cambio de funcionalidad en este amplio edificio público, pudiendo apuntar quizás a un posible aprovechamiento del espacio como cercado para ganado, dada la amplia superficie cercada por una cinta muraria, y un nuevo acceso más estrecho; sin embargo, en el estado actual, con los datos que se tienen, desconocemos con certeza cuál pudo ser la nueva funcionalidad a la que estuvo destinado. De igual forma no es conocido el número total de compartimentaciones ubicadas en el ángulo suroeste, las cuales podrían arrojar más datos al conjunto de este edificio y a los momentos de abandono del mismo. Lo que sí parece fuera de dudas es que en un momento tardío, muy probablemente en el mismo contexto de abandono de la ciudad y desaparición del modelo munici$\mathrm{pal}$, se produce el reaprovechamiento de un espacio destinado, entre otras funciones, para la práctica gimnástica, de modo parecido a lo que está sucediendo en el antiguo espacio forense que, como vimos en páginas iniciales, es aprovechado con nuevas funciones domésticas. Creemos desde esta perspectiva que muy probablemente estas fases tardías localizadas en ambos recintos se habrían desarrollado muy próximas en el tiempo.

Como vemos tras el análisis de los elementos urbanos que hasta el momento se han podido excavar, para estos momentos de la segunda mitad del s. III d.C. la ciudad ha entrado en un claro colapso, la administración municipal ha desaparecido, quizás algunas décadas antes, ya no existe esa elite urbana dirigente encargada de costear las reparaciones y el mantenimiento de la ciudad, sus espacios mostrarían un estado ruinoso, sirviendo de cantera para nuevas construcciones en los establecimientos rurales del entorno y reaprovechando todos sus materiales de construcción, a este respecto podríamos mencionar la acumulación de mármoles que se constató en el foro en uno de los 
sondeos, donde se concentraban machacados preparados para hacer cal con ellos, al igual que sucede con el material escultórico hallado en las proximidades de la aedes y en la propia cella, o incluso a los restos constructivos que se constatan en villae como la Mazmorra, la cual despunta en este periodo y muy probablemente utilizara materiales del entorno urbano.

Paralelamente se está produciendo el abandono de las casas, de manera progresiva y gradual, y la ocupación de otros espacios públicos destinados ahora a una funcionalidad doméstica, como las compartimentaciones del foro, de tal manera que la ciudad contará con una población escasa, prácticamente inexistente cuando comience el s. IV, siendo la ciudad solamente un cúmulo de edificios ruinosos, de los que se seguirá extrayendo material constructivo, mármoles, metales, etc. en el expolio y saqueo propios de este periodo. Ello coincidirá con la tónica general que se registra en Hispania, así Ausonio en el s. IV d.C., en una carta a Paulino de Nola, cita sitios desérticos como Bilbilis, Ilerda, Calagurris, éste le contesta que como aquellas, había otras muchas entre los ríos Betis y Ebro (Epist. 29, 56-59).

\section{La transformación del Ager}

Al igual que sucede en el ámbito urbano, el campo sufrirá un proceso de transformación que marcará nuevas pautas en el poblamiento y explotación de los recursos. Obviamente la crisis con la que se inaugura el s. III d.C. se dejará sentir en el área produciéndose una recensión y estancamiento en la producción, que sin duda afectarían al comercio y las transacciones económicas. Al análisis efectuado para el medio rural han sido de especial importancia las analíticas palinológicas realizadas, así como los estudios realizados para las diferentes Cartas Arqueológicas de Aroche, y los Picos de Aroche (CAMPOS, BATANERO Y MEDINA, 2004; PÉREZ, 1987).

En el periodo comprendido entre el s. III-IV d.C. hay evidencias paleoecológicas que constatan la recuperación del encinar local. La reaparición de biomasa arbórea propia de este ambiente ecológico (Quercus suber type, Juniperus) junto con la presencia residual de taxones propios de la maquia arbustiva (Calluna, Rica arborea type, Cistus Monspeliensis) así lo determinan. Este hecho es debido a dos factores esenciales, el primero la erradicación de prácticas de incendios, aplicadas en las labores de roturación y cultivo, registrada en el periodo del s. II-III d.C. y que perdura en esta etapa cronológica. El segundo, determinado por la respuesta que presenta este tipo de vegetación ante episodios de fuego, dado que crecen rápidamente tras ello, siendo capaces de recuperar su población tras un corto espacio de tiempo. Así en este misma secuencia que exponemos, hay evidencias paleobotánicas que lo corroboran, dado que la cobertura arbórea representa un 60\% frente a la herbácea con 20\%. Esta evolución por parte de los tipos forestales propiciaría la recuperación de la fisionomía autóctona del paisaje del entorno del yacimiento. Por su parte esa escasa vegetación herbácea presenta unos taxones propios de zonas de pastos que junto con la presencia de determinados hongos coprófilos (Polyadosporites 30\%) nos sugieren actividades pastoriles y ganaderas. Además en esta secuencia no se registra polen de cereal y las poblaciones herbáceas asociadas a cultivos han disminuido, por lo que se puede deducir que las prácticas de cultivos cerealísticos decrecieron, o incluso desaparecieron casi por completo, en este periodo cronológico. Esta será la dinámica con la que se inicie la tardo antigüedad (s. IV d.C.) donde el polen arbóreo supera un 65\% del total, mostrando un paisaje densamente forestado. El bosque esclerófilo mediterráneo se encontraría en proceso de recolonización, caracterizado por especies propias de las etapas sucesivas, done se incluirían Quercus suber type y matorrales degradativos (Cistus monspeliensis, Myrtus), quedando registrado un escaso porcentaje de polen de cereal (2\%), testimonio de una producción y cultivo cerealístico reducido y marginal (YAÑEZ, 2007: 553, 554), acorde con un asentamiento poblacional de las mismas características, reducido y disperso.

De estos resultados, unidos al estudio del contexto de decaimiento urbano, se establecen unas nuevas pautas económicas que verán en 
el campo importantes transformaciones. Ello se traduce en un poblamiento disperso, donde los cultivos ven una importante reducción e incluso en momentos de la segunda mitad del s. III d.C. prácticamente no tienen presencia, hasta que iniciado el s. IV se detecten nuevamente taxones de especies cultivables en un escaso porcentaje, como consecuencia quizás de una pequeña reactivación agraria en el marco de un autoabastecimiento y posible comercialización. Igualmente parece que subsistió durante todo el siglo tercero la actividad ganadera, prevaleciendo sobre la agricultura. La imagen que se transmite ahora del ager es la de un espacio de dehesa donde el encinar recupera terreno volviendo a los siglos precedentes anteriores a la ocupación romana y el establecimiento colonial.

La economía verá una recesión o estancamiento, manifestado como vemos tanto por las evidencias del porcentaje de especies cultivables documentadas en los análisis, como por la interrupción y decaimiento del comercio, el cual se verá reducido o incluso llegará a desaparecer para el caso de algunos productos, al menos con las redes de distribución tradicionales. Prueba de ello es la inexistencia en el repertorio cerámico de los envases de transporte de salazones correspondientes a los s.s. III-IV. Del análisis realizado al material en superficie de los yacimientos rurales del entorno se comprueba que existe una escasísima, o nula, presencia de envases de transporte de estos productos a lo largo de todo el periodo imperial, mientras que en la ciudad su porcentaje es elevado en los momentos correspondientes a los s. s. I-II, debido a un comercio fluido con los centros productores de la zona costera, no constatándose para los envases propios de la siguiente centuria. De ello se deduce que estos productos provenientes del litoral, se concentraban y comercializaban en el mercado urbano, dado que en el entorno rural existe una casi nula presencia de envases de transporte, y desde ahí se abastecía la demanda del entorno. Una vez iniciado el proceso de crisis en la ciudad, con mayor fuerza en el segundo tercio del $\mathrm{s}$. III d.C., los mercados urbanos simplemente desaparecieron, quizás debido también a una menor demanda, con lo que las redes de dis- tribución y comercialización se vieron afectadas, descendiendo y desapareciendo la importación de estos productos.

Paralelamente a esta contracción comercial, que llevará pareja la desaparición en las redes de distribución de algunos productos como las salazones, debido al colapso de los mercados urbanos, la producción agraria, tal y como indicábamos líneas más arriba, ve una reducción de especies cultivables. A este respecto basta recordar como los análisis palinológicos confirmaban la presencia de olivar para los siglos I-II d.C., conviviendo con el cereal en unos porcentajes aceptables, que revelan un probable índice productivo que no solo estaría destinado al autoabastecimiento, sino que permitiría un excedente para su comercialización. Para momentos del s. III d.C., en los diagramas polínicos no se registra presencia de olivar; por lo que respecta al cereal, irá disminuyendo a lo largo de la centuria para en momentos avanzados ser inexistente. Solamente, como vimos, se producirá un repunte en el s. IV d.C, constatándose polen de cereal para estos momentos, escaso por supuesto si se le compara con siglos anteriores, pero que evidencian un mínimo productivo destinado al autoabastecimiento de una escasa población. Llegados a este punto podríamos hacer un especial inciso. Resulta del todo significativo, como en estos momentos durante el último cuarto del s. II y el III d.C. se producirá una época de recesión en las minas, el inicio de la crisis minera, debido no a una carencia de minerales, sino a la quiebra general del sistema económico, la puesta en producción de minas con mayor rentabilidad en Britania o Dacia, etc. (CHIC, 2005: PÉREZ, CAMPOS Y VIDAL, 200 I: 429; PÉREZ, 2006: 105). Ello conllevo el desplome de los mercados, dado que las zonas productivas agrarias de campiña en la Tierra Llana y el ager aruccitanus eran los principales proveedores que abastecían la demanda de la población minera, con la caída productiva en las minas y el cambio de orientación económica, que a partir de ahora encontrará en las salazones de la costa un renovado sector en expansión, la demanda de productos provenientes del territorio de Aroche, aceite y cereal, cesaron (PÉREZ, CAMPOS Y VIDAL, 200I: 43I). Con ello se 
podría decir que el desplome de la minería en la zona del Andévalo llevó parejo la caída del sector agrario, a partir de ahora marcado por el autoabastecimiento tanto en la Tierra Llana como en la Sierra, especialmente en la segunda, dado que para el caso de los núcleos urbanos ubicados en la primera de las zonas la accesibilidad a los recursos pesqueros y la transformación de los mismos compensó la crisis del sector agrario y por ende tiraría del mismo, mientras que para la zona productiva de Aroche supuso su irremediable crisis y decaimiento productivo, comercial y económico, condicionante que vendría a sumarse a los ya existentes y que acentuarían el abandono del modelo de vida urbano. En esta dinámica se entienden por tanto los resultados palinológicos que mostraban una inexistencia de especies cultivables para momentos del s. III d.C., de la misma forma que para el s. IV se constata un pequeño porcentaje, que llamativamente coincide con la puesta en marcha de la explotación minera tras las reformas llevadas a cabo por la administración imperial de Diocleciano y Constantino, cuando algunas minas de Riotinto vuelven a tener producción y actividad como demuestran los escoriales y la epigrafía (PÉREZ, 2006: 106; CILA I, 30). Sin embargo para estos momentos del s. IV la realidad será totalmente diferente a la existente en centurias pasadas, ahora ya no existe un núcleo urbano y el campo ha sufrido importantes transformaciones que lo acercan más al modelo de explotación bajoimperial.

En este contexto, el ámbito agrario verá surgir ahora importantes fundi, con amplias dependencias residenciales y agrarias que surgirán o se consolidarán a lo largo del s. III y IV, asumiendo el rol de puntos articuladores de la nueva implantación en el territorio, ahora con un marcado carácter disperso. A estas villae se retirará la aristocracia urbana, la cual ya no residirá en la ciudad agobiada por el peso de las onerosas magistraturas municipales (RODRÍGUEZ, 1972: 182). Ello quedará enmarcado en el contexto general que se produce para la Betica en estos momentos, así ya a fines del s. II d.C. se observa una paulatina reducción de villae, con variantes según la zona, que se relaciona con los cambios que se producen en la propiedad y el modo de explotación, además ahora éstas comienzan a hacerse más monumentales y complejas (PADILLA, 1999: 53; FORNELL, 2005: 589). Muestra de esta argumentación es el yacimiento de Fuenteseca, a unos $12 \mathrm{~km}$ de Arucci Turobriga y ubicado en una fértil llanura regada por el Chanza. Este asentamiento despuntará ya en momentos de la segunda mitad del S. II d.C. mostrando continuidad en el III-IV dado que son recurrentes los fragmentos de sigillata africana tipo Hayes 5 I (PÉREZ, 200 I; RODRÍGUEZ, 2003), conservándose restos de mosaicos, enterramientos turriformes, otros en sarcófagos de plomo hoy día perdidos, etc. que hablan del poder adquisitivo de sus propietarios en un momento de cambios y transformaciones donde se pasa de un mundo urbano, dirigido desde la civitas a una ruralización cada vez más acentuada, ahora sus propietarios prefieren enterrarse en sus dominios rurales, la ciudad ya ha perdido el protagonismo de épocas pasadas. Similar tendencia mostrará el yacimiento de la Zafra, con una extensión de unas dos hectáreas, con importantes construcciones y evidencias, al igual que Fuenteseca, de enterramientos en sarcófagos de plomo, o La Mazmorra (Fig. 8), con numerosos restos en superficie depositados hoy día en la Colección Municipal, algunos tan significativos como una moneda de Constante (337-350 d.C.). Todas ellas quedarían ubicadas en las proximidades o flanqueando la vía que pasando por Arucci y la mansio de Fines llegaría a Pax lulia uniendo el territorio provincial (RUIZ, 2004).

Probablemente antiguos vici asumen ahora la centralización y redistribución de la producción agropecuaria, en torno a los cuales existen pequeñas casas conformando aldeas de escasa extensión las cuales perdurarán durante todo el s. IV.Testimonio de ellas pueden ser las Cefiñas, hoy día una aldea de Aroche donde se documentó una importante necrópolis tardía asociada a un pequeño poblamiento, y de donde proceden algunos materiales como una Lamboglia 5IA/Hayes 59, que ofrecen una cronología entre el 320-380 d.C. Similar proceso se daría en Santa Eulalia, ubicada en el término de la actual Almonaster la Real cercana a la aldea de El Patrás, pero que en época romana quedaría adscrita al ager aruc- 
citanus. Este asentamiento se establece como un vicus minero ya en época altoimperial, desde donde se controlaría la producción de los filones próximos, además se aprecian en una amplia superficie restos constructivos que denotan cierta importancia del poblamiento aquí asentado (LUZÓN, 1975: 317 ; PÉREZ, 2008: 290). Al igual que en Fuente seca o la Zafra existen importantes restos constructivos, como es el caso de otro sepulcro turriforme, aprovechado actualmente en los cimientos de la Ermita de Santa Eulalia.

Igualmente se vuelven a ocupar asentamientos que habían sido abandonados como producto de la política de contributio de Roma en momentos del cambio de era y que mostraban una secular ocupación. Este será el caso de Las Peñas y su entorno más inmediato como el yacimiento de Miradero, o en la finca de Los Benitos donde se constatan indicios de un poblamiento correspondiente a los siglos tardoantiguos, como así se desprende del lugar de enterramiento en los que aparecen los denominados jarros tardorromanos (PÉREZ, 1987: 28; CAMPOS, BATANERO Y MEDINA, 2004).

\section{Consideraciones Finales}

A modo de síntesis de las ideas expuestas en este trabajo se comprueba tras el análisis de los datos que para estos momentos se tienen que la ciudad de Arucci Turobriga verá una breve continuidad en el modelo de vida urbano y municipal durante las primeras décadas del s. III d.C. como así lo atestiguan diversos elementos como las terracotas de culto proveniente de los sacella del foro, materiales arquitectónico-decorativos, etc. Durante casi todo el periodo correspondiente a la dinastía severa los órganos constitucionales parecen dar muestras de continuidad, sin embargo a fines de este periodo se atisban los primeros síntomas o indicios de abandono, en la plaza del foro y en diversas dependencias aparecen ahora cobijadas nuevas funcionalidades domésticas artesanales, así en salas como la curia máximo espacio de representación del poder municipal constituido se aprecia un importante abandono representando por un nivel de expolio y la compartimentación de la estancia. Similar suerte parece correr la sala de los ediles, dividida en dos y abandonando sus funciones y la riqueza de sus materiales broncíneos a la suerte de los expolios, de los que se salvaron diversos elementos como un decempondio (BERMEJO Y CAMPOS, 20 I0). De manera paralela se producirá el establecimiento de diversas compartimentaciones en el pórtico doble con funciones domésticas, cegándose igualmente la entrada del foro.

Estos síntomas de cambio se producen igualmente en edificios como las casas, donde se aprecian indicios de abandono para los momentos del s. III d.C. avanzado, o en la muralla, con episodios de reconstrucción de escasa calidad y empleando todo tipo de materiales, producto quizás de la prisa y el medio, cuyos lienzos aparecerán en ruinas a mediados de la centuria.

Es pues con todo, que tras las primeras décadas del s. III d.C. la ciudad entrará en un proceso de decaimiento sin recuperación que supondrá su muerte definitiva tanto institucionalmente como habitacionalmente, aunque esta última parece durar aún algunas décadas más, existiendo una población residual que quizás alcanzó el s. IV d.C., como demuestran diversos elementos cerámicos recuperados del área forense. Ello nos traduce la idea de que la antigua ciudad se convirtió en estos momentos en la residencia de una población muy residual, además de una importante cantera de reaprovechamiento de materiales para la construcción de los importantes complejos residenciales rurales que despuntaron en el territorio en estos momentos.

Será ahora en el ámbito del antiguo territorio donde se produzca una importante concentración de la propiedad que verá la aparición de extensos fundi, con significativas áreas de residencia. Algunas villae despuntan en extensión y monumentalidad, Fuenteseca, La Zafra, La Mazmorra, alcanzando el s. III con un estancamiento económico que se verá reflejado en la producción agraria, en una recesión del comercio, y en definitiva el colapso del modelo económico propio de los siglos I y primera mitad del || d.C. Durante todo el s. III d.C., 
en las que muchos asentamientos rurales no muestran continuidad, incluso desde algunas décadas antes, se adivinan síntomas de una cada vez mayor desarticulación del modelo económico tradicional, la ciudad irá perdiendo peso hasta desaparecer como centro administrativo y económico, las redes comerciales se han visto afectadas, y se está produciendo una progresiva concentración de la propiedad, hecho que acabaría modificando el paisaje agrario. Todo ello debido a factores como el endeudamiento del campesinado, relaciones familiares de las antiguas élites urbanas, ocupación del ager subcesiva, etc. que verán aparecer, ya en el último tercio del s. Il d.C., la progresiva transformación de la propiedad mediana basada en la mano de obra esclava al predominio de los trabajadores en régimen de colonato en el ámbito de la gran propiedad (FORNELL, 2005: 590). Prueba de esta situación en el ager aruccitanus es la falta de continuidad que muestran, al menos con los datos disponibles actualmente, el importante cinturón de villae que se documentaba en torno al núcleo urbano para momentos altoimperiales, en favor de solo unos pocos núcleos algunos de ellos analizados líneas arriba.

Para finalizar, una de las principales características propia de estos momentos, y que marcará la tónica de los futuros siglos tardoantiguos, será la existencia de un poblamiento disperso, que en algunos casos ha vuelto a los patrones de asentamiento prerromanos, de lo que se deduciría en última instancia que el establecimiento del mundo urbano por parte de Roma supuso un modelo ficticio en una zona donde tradicionalmente éste era ajeno. Ahora bien ello no significa que tras el periodo de los s.s. I-II y principios del s. III d.C. se vuelva por completo a la situación propia de los siglos prerromanos, dado que no se registran los mismos patrones de asentamiento en alturas, ni contingentes poblaciones celtici, el mismo sistema productivo, etc. La situación ha cambiado por completo, existe un poblamiento disperso en efecto, pero ahora asentado en grandes fundi, que ocuparan el antiguo ager centuriado de la ciudad. Todo este proceso marcaría una cada vez más acentuada ruralización, donde la antigua elite urbana irá transformándose en posesores de grandes propiedades. Así mientras que otras ciudades béticas fundadas ex novo, o bien herederas del mundo prerromano, mantendrán una continuidad en su poblamiento, con las transformaciones propias de los s.s. III-IV d.C., la ciudad de Arucci Turobriga se convertirá en un despoblado en ruinas, la cual pervivirá en la memoria colectiva de las poblaciones del entorno, como demuestra el secular expolio de sus materiales y la dinámica del poblamiento próximo en los siglos tardoantiguos y altomedievales, que recalará en la zona correspondiente al yacimiento de la Ladrillera a escaso kilómetro y medio, y posteriormente en el poblado medieval del Castillo de Aroche.

\section{BIBLIOGRAFÍA}

ARCE, J. (1981):"Inestabilidad política en Hispania durante el siglo II d.C.", Archivo Español de Arqueología 54. Madrid. Pp. $101,115$.

-(1993):"La transformación de Hispania en época tardorromana: paisaje urbano y paisaje rural", Actas del III Congreso estudios medievales, De la Antigüedad al Medievo s.s. IV-VIII. León. Pp. 387, 392.

BALIL, A. (1957): “Las invasiones germánicas en Hispania en la segunda mitad del s. III d.C.", Cuadernos de trabajo de la Escuela Española de Historia y Arqueología en Roma, IX, I. Roma. Pp. 95, I32.

BERMEJO, J. (20 I Oa): "La curia de la ciudad hispanorromana de Arucci/Turobriga", Actas del IV Encuentro de Arqueología del Suroeste (Aracena, Huelva), Pp. 999, 1010

- (20।0b): "Las terracotas femeninas del foro de Aruccil Turobriga. ¿Testimonio de culto a las Augustae et Divae?", Anales de Arqueología Cordobesa, n 21 , Córdoba.

BERMEJO, J. Y CAMPOS, J. M. (20।0): "La sala de los ediles de Arucci/Turobriga. Officina Ponderaria Aruccitana". Saguntum 4I, Valencia, Pp. 9,20.

CAMPOS, J.M., BATANERO, D. Y MEDINA N. (2004): Carta Arqueológica de Aroche. Inédito.

CAMPOS J. M.Y BERMEJO J. (2007): "Manifestaciones del culto imperial en la ciudad hispanorromana de Turobriga", Actas del Congreso Internacional Culto Imperial: Política y poder, L`erma di Bretschneider. Roma, Pp. 25I, 274.

CORELL, J. (1988): "Inscripción referente a un primipilo muerto in bello maurico ¿Un nuevo testimonio de las invasiones moras en la Bética en el siglo II?', Archivo Español de Arqueología n 61, Madrid, Pp. 298, 304.

CHIC, G. (2005): "Marco Aurelio y Comodo. El hundimiento de un sistema económico", La Hispania de los Antoninos en Actas del II Congreso de Historia Antigua, Valladolid, Pp. 587, 596. 
DELGADO, S. (2007): "Terra sigillata y paredes finas en Turobriga. (Aroche, Huelva) Campañas 2004-05", en Vipasca Arqueología e Historia $n^{\circ} 2,2^{a}$ serie, Aljustrel, Pp. 354, 363.

FORNELL, A. (2005): "Evolución de las villae béticas durante la dinastía antonina", La Hispania de los Antoninos, en Actas del II Congreso de Historia Antigua, Valladolid, Pp. 587-596.

GRÜNHAGEN, W. (1982): "Cronología de la Muralla de Munigua", Homenaje a Sáenz de Buruaga, Pp. 315, 328.

LUZÓN, J.M‥ ( 1975): “La romanización”. Huelva: Prehistoria y Antigüedad, Madrid, Pp. 269-320.

PADILLA, A. (1989): La provincia romana de la Betica (253-422 d.C.).

PÉREZ, J.A. (1987): Carta arqueológica de los Picos de Aroche. Huelva.

-(200 I): "Colonización romana y producción agrícola en Arucci/Turobriga", Anas 14, Mérida, Pp. 103, 118.

-(2006): La huella de Roma. Huelva.

- (2008): "Las inscripciones funerarias de comienzos de siglo en Huelva. ¿Migración o colonización?", Espacios, usos y formas en la epigrafía hispana en época antigua y tardoantigua, Homenaje al Dr. Armin Stylow. Anejos de AEspA. XLVIII, Pp. 285, 295.
PÉREZ, J.A., CAMPOS, J.M.Y VIDAL, N. DE LA O. (200 I): "Producción y comercio en el oeste de la Bética según la circulación anfórica". Actas del Congreso Internacional ex Baetica Amphorae, Conservas, aceite y vino de la Bética en el imperio romano, Vol. I, Cádiz, Pp. 427, 438.

RUÍZ,J. M. (2004): "Arucci y el itinerario De Esuri Pace lulia". Actas del II encontro de arqueologia do sudoeste peninsular, Faro, Pp. 207, 214.

RODRÍGUEZ, J.F. (1972): "Aspectos del siglo III d.C. en Hispania". Hispania Antiqua, Revista de Historia Antigua II, Vitoria Pp. 179, 201.

RODRÍGUEZ, R. (2003): La ciudad romana de Arucci y el yacimiento arqueológico de Fuenteseca. Nuevos datos para el estudio de la romanización de los Llanos de Aroche (Huelva), Trabajo de Investigación de Tercer Ciclo, Universidad de Huelva, Inédito.

SCHATTNER,T. (2003): Munigua cuarenta años de investigaciones. Monografias de arqueología, Junta de Andalucía.

YAÑEZ, C. (2007): "Estudio Palinológico del Yacimiento arqueológico de Turobriga (Aroche, Huelva)". Proyecto de investigación y puesta en valor de la ciudad hispanorromana de Turobriga (Aroche, Huelva). Campañas 2005/2006. Memoria cientííca, Vol. III Anexos, Delegación Provincial de Cultura, Inédito, Pp. 535, 575. 


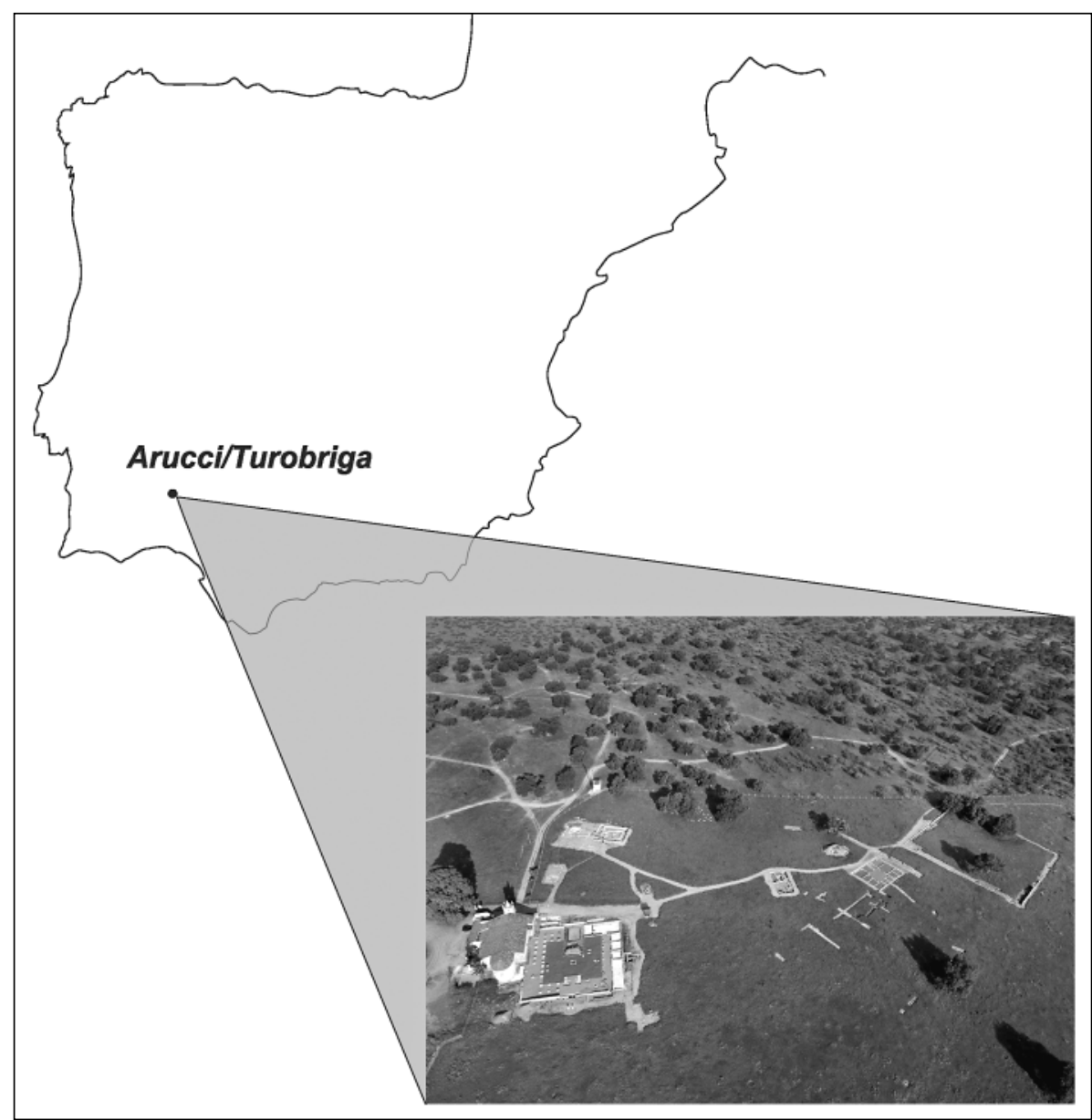

Fig. I. Situación de Arucci Turobriga

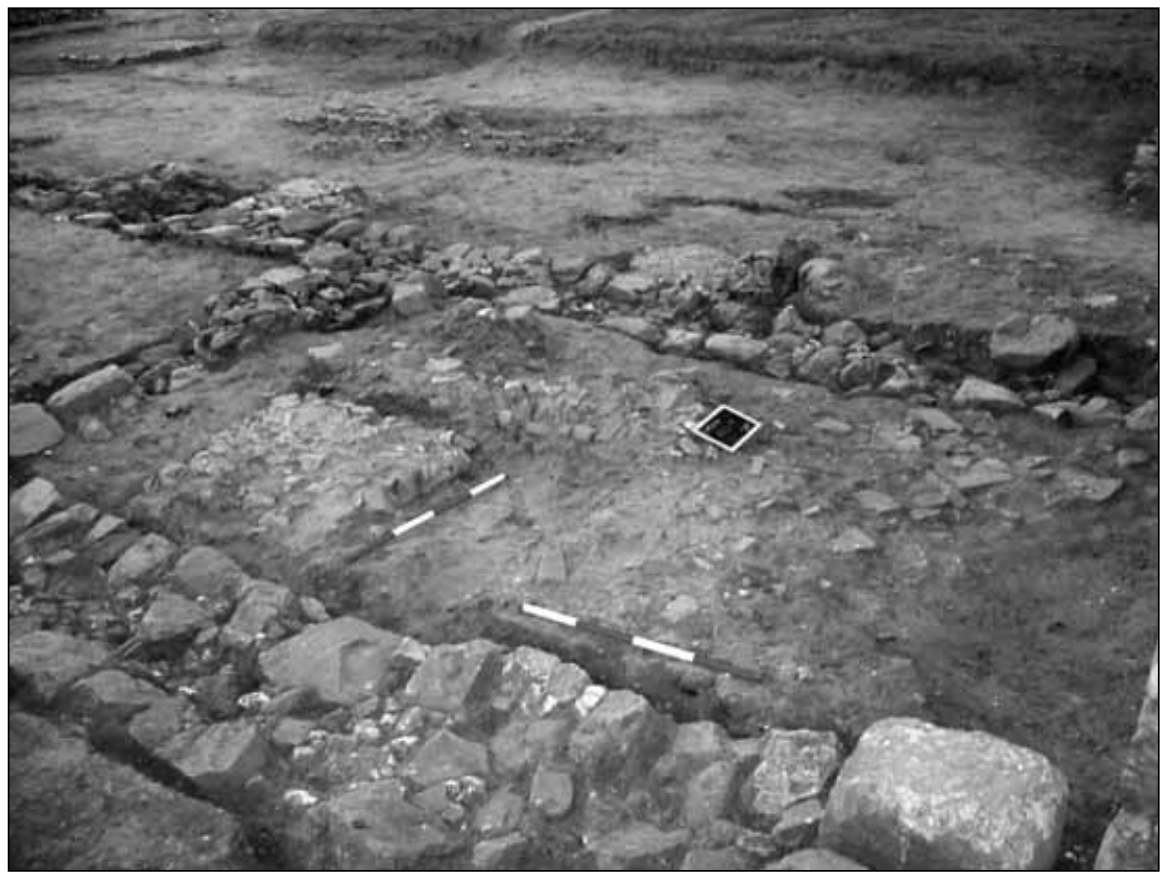

Fig. 2. Compartimentaciones posteriores en la porticus duplex del foro 


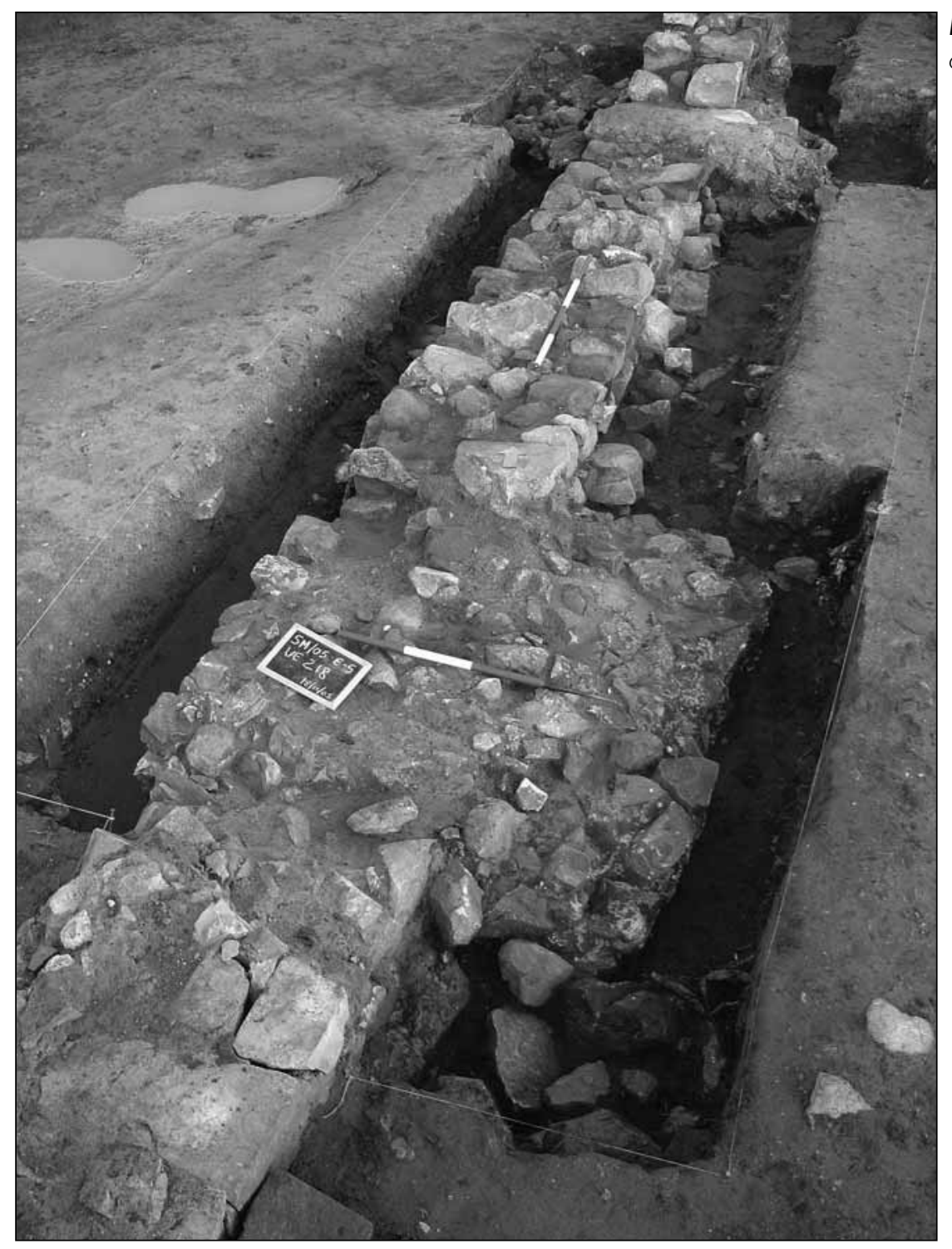

Fig. 3. Muro de cegamiento del vano de acceso al foro

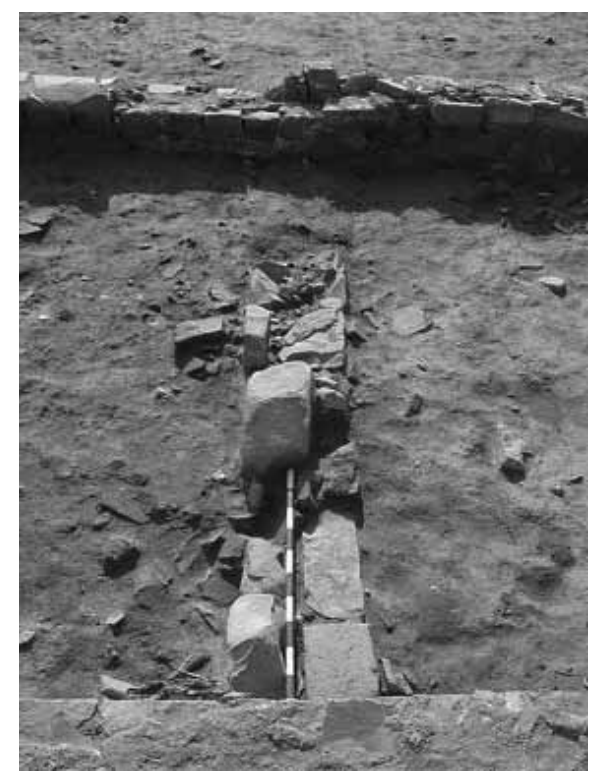

Fig. 4. Muro divisorio de la sala de los ediles 


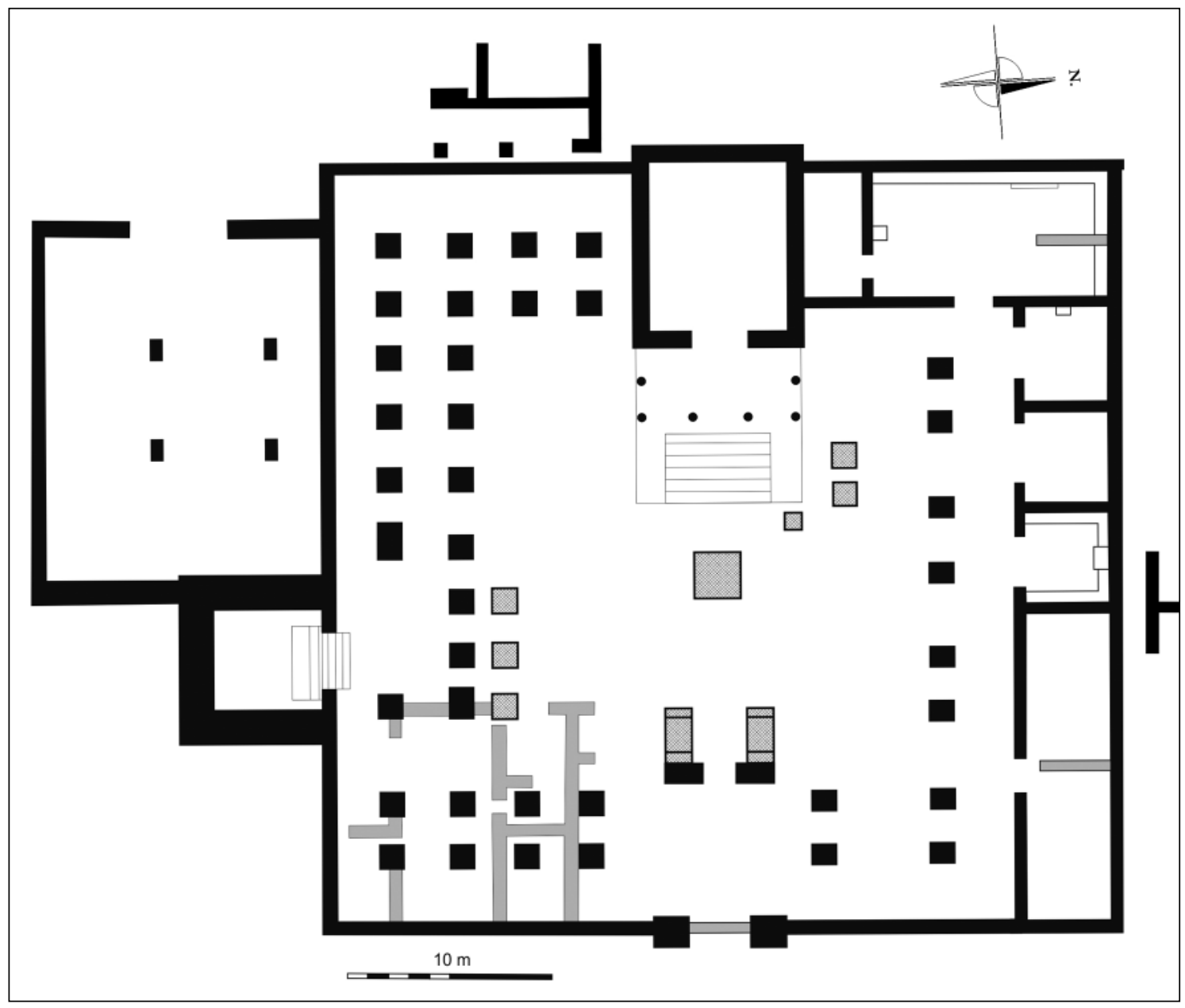

Fig. 5. Plano del foro con fase tardía

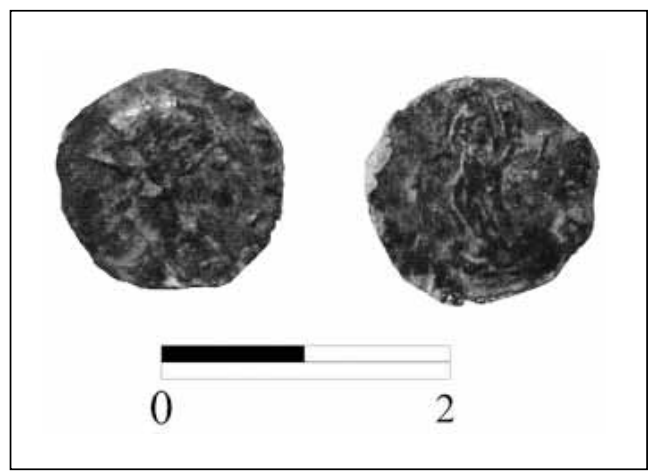

Fig. 6. Antoniano de Claudio II el gótico.

Fig. 7. Estrechamiento del acceso al campus

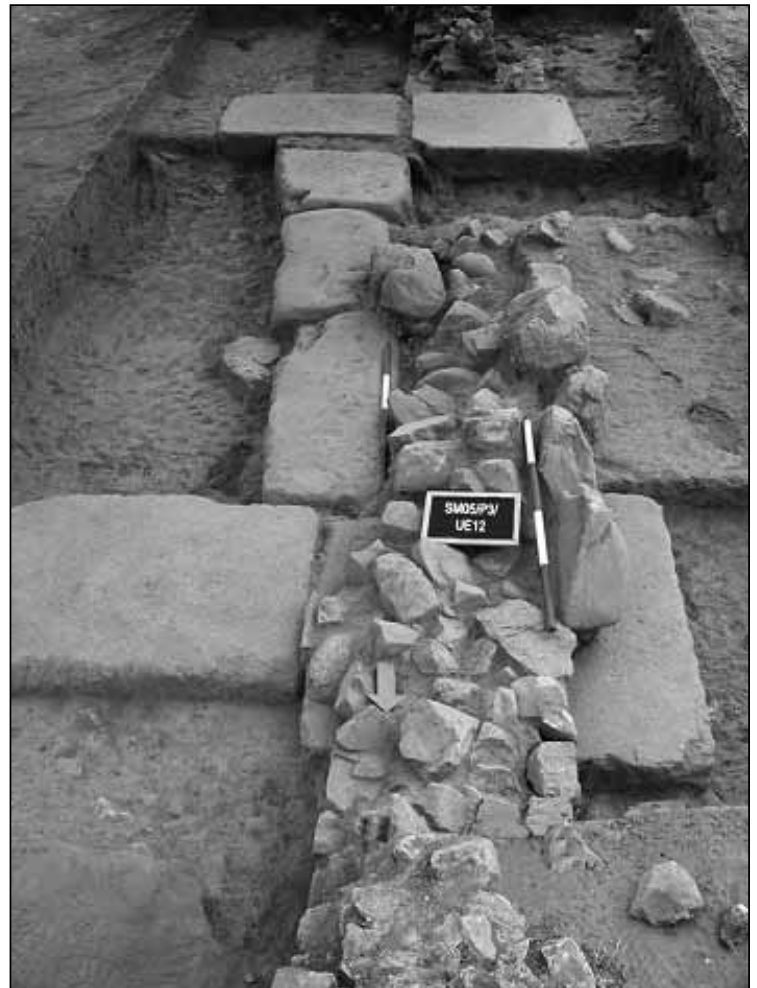




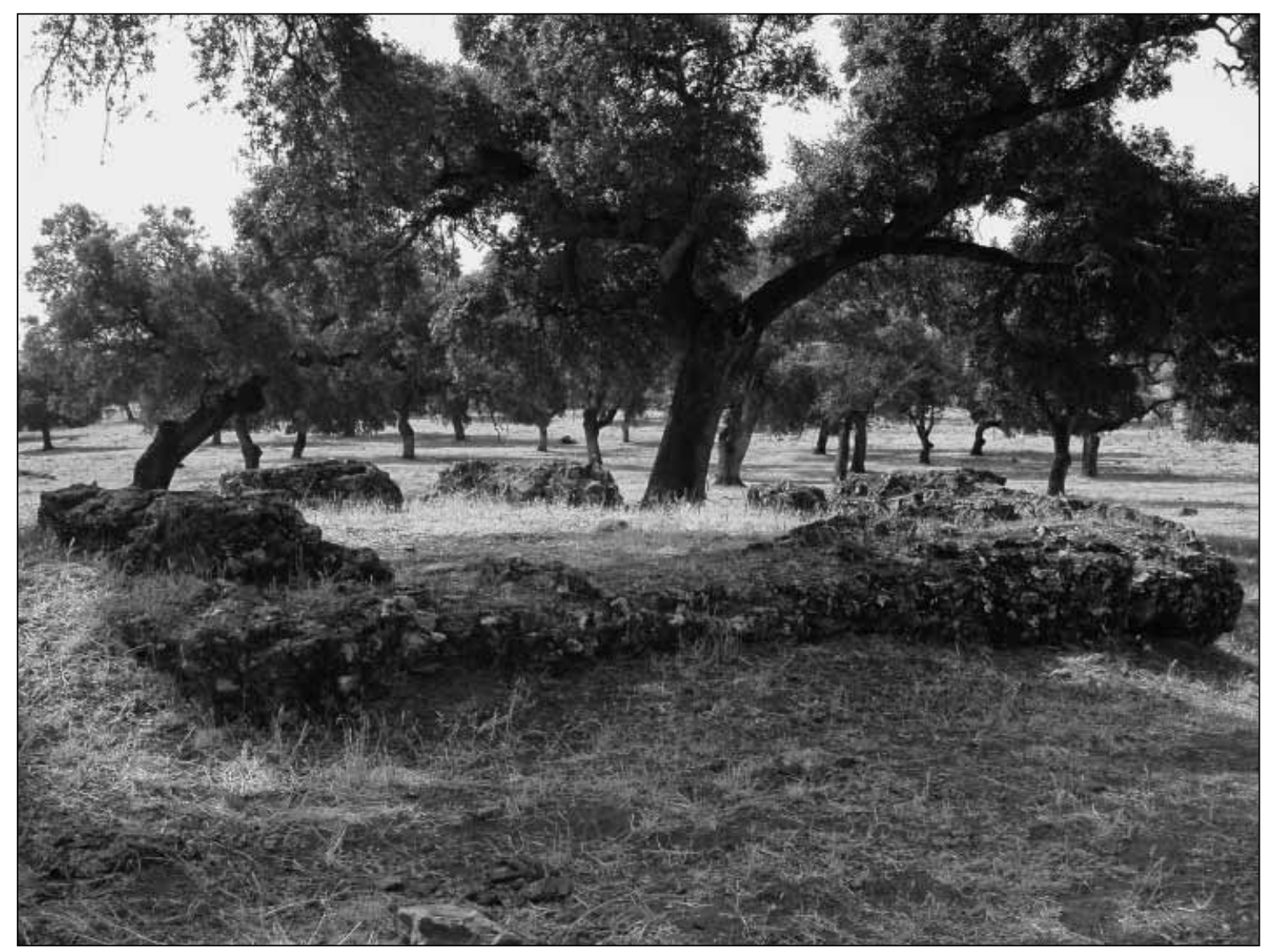

Fig. 8. Algunas de las estructuras que se aprecian en superficie en la finca de la Mazmorra correspondientes a una villa 